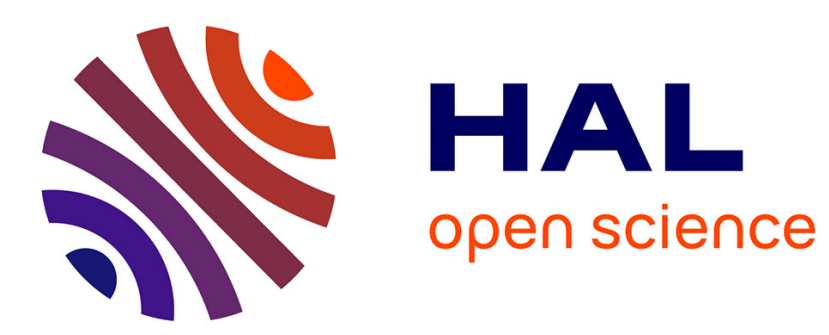

\title{
Developing communicative postures
}

Pauline Beaupoil-Hourdel, Camille Debras

\section{To cite this version:}

Pauline Beaupoil-Hourdel, Camille Debras. Developing communicative postures: The emergence of shrugging in child communication. Langage, Interaction et Acquisition / Language, Interaction and Acquisition , 2017, 8 (1), pp.89 - 116. 10.1075/lia.8.1.05bea . hal-01626189

\section{HAL Id: hal-01626189 \\ https://hal.science/hal-01626189}

Submitted on 14 Jan 2021

HAL is a multi-disciplinary open access archive for the deposit and dissemination of scientific research documents, whether they are published or not. The documents may come from teaching and research institutions in France or abroad, or from public or private research centers.
L'archive ouverte pluridisciplinaire HAL, est destinée au dépôt et à la diffusion de documents scientifiques de niveau recherche, publiés ou non, émanant des établissements d'enseignement et de recherche français ou étrangers, des laboratoires publics ou privés. 


\title{
Developing communicative postures The emergence of shrugging in child communication
}

\author{
Pauline Beaupoil-Hourdel and Camille Debras \\ Sorbonne Nouvelle University / Paris Nanterre University
}

\begin{abstract}
This article analyses the development of a composite communicative posture, the shrug (which can combine palm-up flips, lifted shoulders and a head tilt), in a video corpus of spontaneous interactions between a typically developing British girl, Ellie, and her mother, filmed at home one hour each month from Ellie's tenth month to her fourth birthday. The systematic coding of every shrug yields a total of 124 tokens (Ellie: 98; her mother: 26), providing results in terms of forms, functions and input. Ellie's first shrug components emerge from nonlinguistic actions and she acquires them one at a time starting with the hands: these features recall the development of complex signs among deaf children of the same age (Reilly \& Anderson, 2002 for ASL). The functions of Ellie's shrugs gradually diversify from the expression of absence at 1;04 to other epistemic and non-epistemic meanings (affective and dynamic). Adult intervention plays a crucial role as adults recurrently equate Ellie's physical movements with speech, thereby contributing to the emergence of their communicative functions as gestural emblems (Ekman \& Friesen, 1969).
\end{abstract}

Keywords: shrug, multimodality, gesture development, gesture compositionality, gestural emblems, first language acquisition, embodied interaction.

\section{Introduction}

1.1 The shrug: a composite posture

Young hearing children do not use gestures only to enter communication (Clark, 1978; Goldin-Meadow, Goodrich, Sauer, \& Iverson, 2007; Iverson, 2010; Iverson \& Goldin-Meadow, 2005; Zlatev \& Andrén, 2009). They also keep gesturing as they start to speak and as they learn to couple gestures with speech to communicate (Andrén, 2010; Capirci, Iverson, Pizzuto, \& Volterra, 1996; Iverson, Capirci, Volterra, \& Goldin-Meadow, 2008; Morgenstern, 2014). Most studies of co-verbal 
communication focus on hand gestures, since they are the most complex and salient articulators mobilised in the visuo-gestural mode during spoken communication. And yet, the literature on sign language and sign language acquisition has shown how, from a very young age, children and adults are also able to use and combine other body articulators (head, face, shoulders, trunk orientation) to communicate (Filhol, Hadjadj, \& Choisier, 2014). In that regard, the posture of shrugging, which is a conventionally used gesture in spoken English as well as in BSL and ASL, is especially interesting to study because of its composite nature. We define the shrug not only as an instance of lifted shoulder but more broadly, following Streeck (2009: 189), as a "compound enactment", which can combine palm-up flips, lifted shoulders, and a lateral head tilt (Kendon, 2004; Streeck, 2009). How does the child learn to combine this posture's multiple features? Are they acquired as a holistic combination, or one at a time? To answer these questions, this study proposes to document the development of the shrug in a typically developing child from one to four years old.

The shrug, identified early on by Darwin (1872) or Efron (1941) has been classified as an "emblem" (Ekman \& Friesen, 1969) or "quotable gesture" (Kendon, 2004: 335), i.e. a gesture with a stable, conventionalised meaning that can be reformulated by a spoken phrase within a given culture. During adult interaction, the shrug and its components mark the speaker's perspective in both spoken and signed languages. The palm-up flip can function as a stance marker in spoken American English as well as in American Sign Language (Shaw, 2013). The head tilt, usually in combination with raised eyebrows (and optionally with the sign IF), is an epistemic marker expressing conditionals in both ASL and BSL (SuttonSpence \& Woll, 1999; Valli \& Lucas, 2000). In spoken French, head tilts seem to indicate perspective shifts (Maury-Rouan, 2011). More generally, among adult speakers, the shrug can contribute to indicate a speaker's distance or disengagement among British adult speakers (Debras, 2013), a speaker or signer's ignorance or uncertainty (Tennant \& Gluszak Brown, 1998: 180 for ASL signers), non-intervention (Kendon, 2004: 275), a disclaimer (Morris, 1994 on facial shrugs) or non-assertiveness (Givens, 1977).

In British and American Sign Languages, the shrug is not classified as a sign (Shaw, 2013 for ASL; Sutton-Spence \& Woll, 1999 for BSL) but as a gesture. Since both ASL and BSL signers and English speakers use it as a gesture, it represents an interesting point of entry into how gesture constitutes an interface between spoken and signed languages (Goldin-Meadow, 2005). Previous studies on gestures have shown that hearing children's gestures can pave the way to language (Iverson \& Goldin-Meadow, 2005) and that the iconic gestures produced by hearing children are similar to the ones produced by deaf children (Bello, Caselli, Pettenati, \& Stefanini, 2010; Pettenati, Stefanini, \& Volterra, 2010; Stefanini, Bello, Caselli, 
Iverson, \& Volterra, 2009; Stefanini, Caselli, \& Volterra, 2007). Research on signed languages has developed tools to account for a construction of meaning that involves a combination of visual articulators (Channon \& van der Hulst, 2011). For that reason, even though the shrug is not a sign, analytical approaches from signed languages could be highly relevant to account for its compositionality within the context of spoken communication. From a developmental perspective, investigating the emergence of shrugging in young children's communication will also cast light on the acquisition of gestural emblems, about which little is currently known.

The compositionality of shrugging raises a number of challenges for its study. A previous study of shrugging among native speakers of British English (Debras, 2013) has shown that shrugging postures can vary both in form and function, although they are unified by a restricted list of formal components. They are also used to express the speaker's distance or disengagement, with various nuances (indetermination, ignorance, affective distance, helplessness) in each context of use. Some crucial questions related to compositionality arise: to what extent can the use of one shrug component be connected with one specific meaning? Does the use of only one versus multiple components indicate different meanings or rather a scale of intensity in the performance of the posture? To what extent can we even be sure that the realisation of a single component is in fact an instance of the whole posture? Since these various shrug components can take on meaning as part of a whole, they must be linked at some level.

To try and describe the link between these parts, we start with the assumption that the combination of components in shrugging is not pure chance, but has physiological motivations. We follow Boutet's $(2008,2010)$ allocentric $^{1}$ formal and physiological approach to gesture, which accounts for gesture units not in terms of iconicity, but based on their formal characteristics and constraints. Meier, Mauk, Cheek and Moreland (2008) have also shown how motoric factors, rather than iconic ones, constrain children's early sign production; the same could be true of speaking children's gestures, which rely on the same articulators as signs. Each point of articulation (hand, forearm, arm, shoulder) has a limited set of degrees of freedom, which in turn constrains the potential movements of the other articulators. For instance, the hand has three degrees of freedom at the wrist: supination/ pronation, flexion/ extension, abduction/adduction (movement towards the index or the little finger). Even though the palm-up and the shoulder lift might look different, Boutet (2008: 103) explains, they are closely related in

1. Boutet $(2008,2010)$ calls his approach allocentric as opposed to the traditional egocentric conception of gesture space. His formal and physiological approach of gesture is allocentric insofar as each point of articulation constitutes a centre of movement, whose degrees of freedom can constrain or be constrained by other articulatory centres. 
terms of proprioception, with the upper arm in intermediate position (i.e. with the elbows close to the ribcage). It is because of such physiological similarities, Boutet argues, that these gestures can happen to express similar meanings in context, such as helplessness for instance (Boutet, 2008: 104). Furthermore, Boutet (2008) explains, when a person flips her palms up and rotates them to the maximum towards the sides, the shoulders will necessarily start to rise because of physical articulatory constraints. We think that Boutet's physiological approach could also account for the link between shoulder lifts and lateral head tilts. When shoulders are lifted, they are not so much moving upward as moving closer to the head. Conversely, when the head is tilted to the side, it is moving closer to the shoulder. In the case of shoulder lifts and lateral head tilts, the movement of the head is visible relative to the shoulder, and vice-versa: one articulator can be used as a contextual enhancer for the other.

So how do hearing children acquire these various components and learn to combine them to express a variety of meanings? So as to account for the posture's compositionality, we think that the posture's components need to be analysed both when they are used separately and in combination. Since signs can combine multiple articulators in sign languages, their acquisition might provide some insight into the acquisition of multi-component gestures like the shrug. Reilly and Anderson (2002) study the acquisition of non-manual morphology among deaf children between 1;00 and 4;11 who are learning ASL, focusing on the facial actions and head movements that express grammatical information (adverbials, negation, wh-clauses) alongside manual signs. Their study reveals three crucial features of the acquisition of compositional signs: first, the linguistic functions of some non-manual (facial) forms are recycled from their emotional functions. Second, children "must analyse the forms independently before they can integrate the manual and the non-manual channels" (Reilly \& Anderson, 2002: 168), and learn each component as a separate morpheme, since they associate one form with one function. Third, "the manual channel takes developmental precedence" (Reilly \& Anderson, 2002: 168) over non-manual morphology. In the linguistic phenomena studied by Reilly and Anderson, the manual sign learned first corresponds to a free morpheme, while the non-manual signs added later correspond to bound morphemes. Although hearing speakers' linguistic morphemes are produced in speech and their gestures do not have precisely defined grammatical meanings, their shrugs remain highly conventional as gestural emblems. For that reason, we hypothesise that some of the phenomena described above (linguistic functions recycled from non-linguistic ones; morphological character of each component; developmental precedence of hand gestures) might also be observed in the development of the shrugging posture. 


\subsection{Background: the adult study}

A starting point for this study is another study (Debras, 2013, to appear) of shrugging as stance taking among young British adults, based on a videotaped corpus of semi-guided conversations between native speakers of British English who are university students (16 speakers, total length: 2 hours and 40 minutes). The two members of each pair of participants were friends and each pair picked and discussed questions about contemporary environmental issues for about 20 minutes. The theme of the environment weaves together political and ethical issues about which the protocol questions were meant to make the participants take stances (e.g. "should we stop using nuclear power?").

The whole data set was annotated in ELAN and spreadsheet software for various gestures, postures and facial variations related to stance taking, among which shrugs and their components. The coding yielded 102 shrugs. The core meaning of shrugging that emerged from the coding was distance and disengagement, confirming Streeck's (2009) analysis of the shrugging posture:

shrugs are actions in which paired body-parts - eye-brows, fingers, hands, forearms, shoulders - are raised and thereby disengaged from any forward movement, any line of action, any active involvement with things (...) The body displays a distanced, less than committed stance, and we usually read this as an expression of the person's attitude towards a proposition, a state of affairs, or an illocutionary act.

(Streeck, 2009: 189-190)

In terms of functions, the 102 tokens of shrugging could be grouped into five consistent semantic categories (first column in Table 1, with corresponding raw numbers in brackets). In each category, the meaning of the shrug is stable enough to be reformulated verbally (second column in Table 1). This confirms the status of shrugging as a quotable gesture: it has "become established as a vocabulary item with a shared meaning, which could be used in place of words" (Kendon, 2004: 325). Furthermore, the glosses of shrugs fall into one of the three major categories of emblem glossing, specifically, "the announcement of one's current state or condition" (Kendon, 2004: 339). The five main meanings of shrugs can be further grouped across three classical stance functions: affective stance, epistemic stance and actions/ attitudes. The majority of shrugs are used to express epistemic stance in this data, yet no generalisation can be made about this result.

In this adult data, the most frequent meaning of shrugs is the expression of common ground and obviousness. This meaning might at first sight stand out as different from the others, but it is actually a mere expression of the speaker's disengagement that lays emphasis on interpersonal knowledge. With this type of you 
Table 1. Stance-taking functions of shrugs among British native adults (Debras 2013)

\begin{tabular}{|c|c|c|}
\hline Non-intervention, non-responsibility (9) & "this has nothing to do with me" & Actions and \\
\hline Helplessness, powerlessness (6) & "I can't do anything about this" & \\
\hline Indifference, rejection (14) & "I don't care about this" & Affective (14) \\
\hline Indetermination, ignorance (29) & "I don't know" & Epistemic (73) \\
\hline Common ground, obviousness (44) & "you know" & \\
\hline
\end{tabular}

know shrug, speakers mean that they do not need to endorse information that is known to them as well as to their interlocutor.

Debras (2013) observed that mouth shrugs (facial shrugs expressed with the mouth, after Morris, 1994: 165) are closely related to the expression of indetermination in the data; the palm-up component is closely linked with actionalattitudinal shrugs expressing helplessness, while multiple components combined to form a fuller-fledged shrugging posture are connected with the expression of affect. Although more data would be needed to confirm these trends as reflecting the general use of shrugging, these results already suggest that shrugging could constitute a gesture family (Kendon, 2004) with distance and disengagement as a common, schematic semantic-pragmatic theme, within which more specific varieties of shrugs based on stable form-function pairings can be found.

While the adult study has shown how complex the shrugging posture is in terms of forms and functions, little is known about how children acquire this complex visuo-gestural communicative resource. How does shrugging become a conventionalised posture in a child's repertoire? In turn, what can the development of a conventionalised, quotable posture like shrugging in child communication tell us about adult communication? Furthermore, does the emergence of shrugging in children's communication confirm distance and disengagement as a semanticpragmatic theme?

\section{The child study: corpus and method}

We investigated the use of shrugging in a 36-hour video corpus of spontaneous interactions between a typically developing British girl, Ellie, and her mother, filmed by Ellie's grandmother at home one hour each month from Ellie's ten months to her fourth birthday. This longitudinal collection of video recordings is part of 
the CoLaJE ${ }^{2}$ corpus. ${ }^{3}$ We coded palm-up gestures, shoulder lifts and head tilts as shrug components and each occurrence in the videotaped data was systematically annotated and coded for various features of its context of use (Kendon, 2004) in spreadsheet software. We coded:

- whether the shrug component was produced with speech or isolated from speech,

- the speech content and the accompanying intonation if applicable,

- the communicativeness of the multimodal utterance (based on contextual features like sequentiality of actions, gaze and intonation, we determined whether the utterance was self-oriented or on the contrary destined to an interlocutor),

- the meaning contribution of the shrug in the simultaneous and sequential context,

- the global function of the multimodal utterance.

In this systematic yet qualitative coding, functions are not chosen in advance. The coding of functions is data-driven: both authors have observed the data multiple times in detail to describe each token as precisely as possible, based on the multimodal, sequential interactional context (e.g. how do interlocutors react to or take up an utterance of the child's that includes a shrug component?). Going through the data several times enabled us to inductively identify functions and/or repeated patterns across the various occurrences. For these reasons, we chose to rely on collective rather than blind coding.

In order to convey fully multimodal analyses of Ellie's shrugs, her MLU was also computed thanks to the CHAT transcriptions in the CLAN software (McWhinney, 2000).

\section{Quantitative results}

Our coding of the data yielded 98 tokens of shrugs produced by the child and 26 tokens performed by her mother.

2. Project Communication Langagière chez le Jeune Enfant (http://colaje.scicog.fr), funded by the French National Agency for Research (ANR), see Morgenstern and Parisse (2012).

3. Recordings and transcripts can be downloaded from http://modyco.inist.fr/data/bilingue/ anglais/ellie 


\subsection{Use of forms}

Figure 1 represents the general tendencies in Ellie's use of shrug components, in raw numbers. This representation shows the low number of shrug components from $2 ; 03$ to $3 ; 02$.

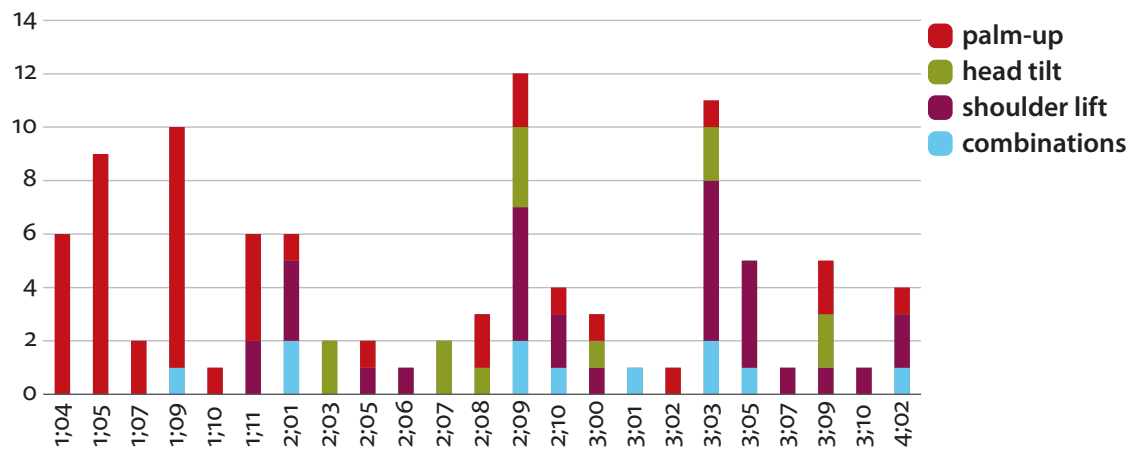

Figure 1. Formal components of Ellie's shrugs in raw numbers

Figure 2 illustrates general tendencies in Ellie's use of shrug components, this time in proportions. One should keep in mind that the numbers can vary considerably from one recording session to the next, because of the child's speech development as well as the diverse activities that she and her mother engage in (for instance, the numbers can be lower when the child is eating than when she is playing).

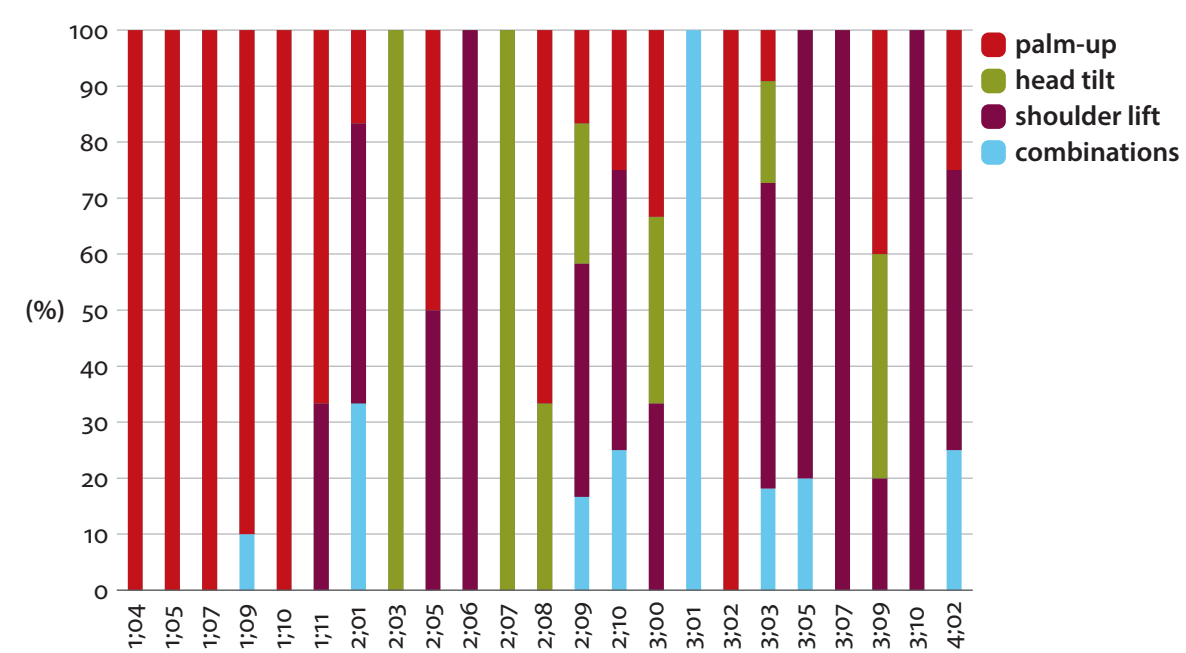

Figure 2. Formal components of Ellie's shrugs in proportions

Ellie produces her first shrug components at 1;04, and from 1;04 to 4;00, three phases stand out. To distinguish the phases, we focused on the forms produced 
and their proportion. From 1;04 to 1;11 (phase 1) Ellie almost exclusively relies on palm-up gestures, which are used in isolation or combined with single-word utterances like done or gone. From 2;01 to 3;02 (phase 2), she starts diversifying her repertoire of shrug components with lateral head tilts and shoulder lifts, used in isolation from other gestural components. From 3;03 to 4;00 (phase 3), a new pattern emerges, in which shrugs (mostly shoulder lifts) are combined with more complex utterances of three or more words.

This decrease in the use of shrug components could be correlated with the fact that her speech grows more complex during that period, especially from 2;03 to $2 ; 09$. In language acquisition, gestures are often described as paving the way for the emergence of speech (Iverson \& Goldin-Meadow, 2005), yet Ellie's data suggests that a different process is at work, namely a more gradual, synergistic development of speech and gesture. Like most typically developing children, Ellie enters communication through her body movements and actions, some of which gradually turn into more schematic and purely communicative gestural forms (BeaupoilHourdel, Morgenstern, \& Boutet, 2015; Morgenstern \& Beaupoil, 2015). This process starts before and includes phase $1(1 ; 04$ to $2 ; 00)$ when she starts combining actions and gestures with one-word utterances. Ellie's speech starts to develop during phase 2 (2;01 to 3;02): at 2;00 she produces about 1.5 words per utterance (MLU: 1.538) while at 3;00 her MLU has almost doubled, with 2.707 words per utterance on average. During that period, her vocabulary diversifies - she acquires more than a hundred new words.

Interestingly, her speech development in phase 2 is synchronised with a drop in the use of shrug components (especially from 2;03 to 3;02, apart from 2;09). One plausible explanation for this pattern is that Ellie acquires the various resources in her communicative repertoire in stages. She first develops mostly the visuo-gestural mode and some premises of speech (phase 1). Then the development of actions and gestures is put on hold, while the development of speech takes over (phase 2). Although they are less frequent, actions and gesture do not disappear during phase 2. Entering phase 3 (at 3;03), Ellie now masters a larger repertoire of spoken forms and starts using gestures more profusely again as she is able to produce more complex speech-and-gesture combinations. The three phases suggest that Ellie develops one mode (speech or gesture) at a time: a single mode remains in focus for a period of several months, and only when Ellie has reached a certain stage of mastery does she start combining it with the other mode again.

Interestingly, Ellie's acquisition of shrug components is organised from distal to proximal articulators: she first uses her hands (palm-ups) before mobilising her (lifted) shoulders and head (tilts) to express herself. This reflects the typical development of children's actions, gestures or signs (Beaupoil-Hourdel, 2015; Blondel, Boutet, Beaupoil-Hourdel, \& Morgenstern, 2017; Boutet, 2008) but could also be 
related with the actional origin of gestures. Hands are complex articulators that are most readily mobilised by toddlers to discover and manipulate objects (i.e. holding, touching, receiving) during the pre-linguistic, sensori-motor stage of development (Piaget, 1952). If we consider gestures as emerging from abstracted, schematic forms of manipulation (LeBaron \& Streeck, 2000; Streeck, 1994), it is no surprise that hands should be used to gesture before head and shoulders, which are not mobilised as much for the manipulation of objects. The slightly delayed use of shoulders (from 1;11) and head (from 2;03) in shrugging postures could be acquired following another path of development, i.e. not so much originating in the child's actions but rather in the child's imitation of adult behaviour (see Section 5 below).

\subsection{Functions of shrugs}

Systematic coding allowed the identification of 14 contextual functions for the 98 shrugs performed by Ellie in the corpus. These functions can be classified into four main categories (as represented in the table below).

Table 2. The functions of Ellie's shrugs

\begin{tabular}{llll}
\hline Absence $44(45 \%)$ & $\begin{array}{l}\text { Deontic functions } 4 \\
(4 \%)\end{array}$ & $\begin{array}{l}\text { Affective functions } \\
23(23 \%)\end{array}$ & $\begin{array}{l}\text { Epistemic functions: } \\
27(28 \%)\end{array}$ \\
\hline - non-presence & - incapacity & - rejection & - denial \\
- non-existence & & - exasperation & - indetermination \\
- end of process & & - non-responsibility & - obviousness \\
& & - indifference & \\
\hline
\end{tabular}

The expression of absence (including expressions of the non-presence or nonexistence of something, or the fact that a process has just ended) is by far the most frequent function in the corpus. Epistemic functions are the second most frequent, followed by affective ones. Even though dynamic functions (i.e. expressing the subject's (in)capacity; Palmer, 2001) are not frequent at all in the data, they are easily distinguished from other modal functions thanks to their interactional context. The corpus suggests that shrugging is related to the expression of stance-taking from an early age: shrugs are used to express epistemicity, affect, or the subject's disposition for action, the three of which are classical stance categories (Englebretson, 2007). Figure 3 represents the use of the four identified subcategories over time: absence, other epistemic functions, affective functions, and dynamic. 


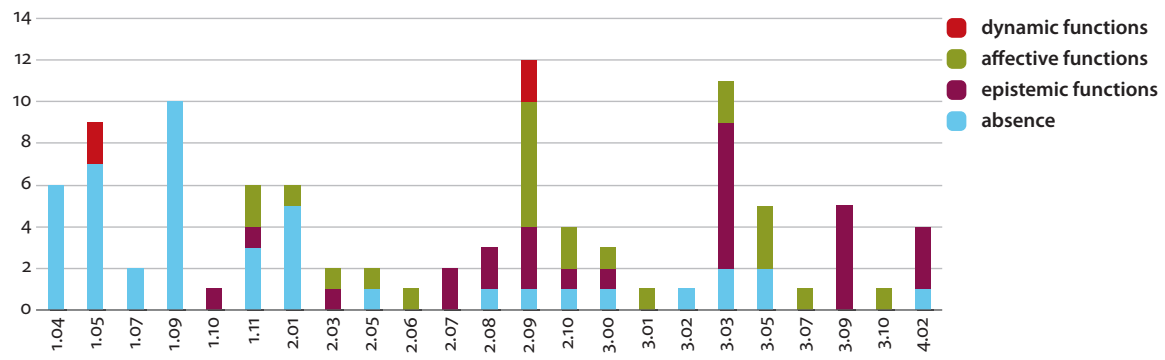

Figure 3. The contextual functions of Ellie's shrug components

Absence is the first function to appear at 1;04. When the child uses a shrug to express absence, it is usually to communicate that something is not there, cannot be found, or that a process is over. Absence is a concrete function with which the child makes a statement about the here and now and the immediate environment that surrounds her. The expression of incapacity is the second function to appear at $1 ; 05$, although it is less frequent in the data. With this concrete yet subjective function, the child communicates not only about the state of the world around her but rather about the extent to which she can influence her immediate environment. From 1;10 on, more subjective, abstract functions appear as shrugs are used to express knowledge and affect. Expressions of epistemic stances (other than absence) and affective stances develop simultaneously.

We also analysed whether Ellie's shrugs were communicative or not, i.e. whether she seemed to shrug just for herself or so as to communicate with an interlocutor. Relying on a range of parameters (gaze, orientation of the body, sequentiality of actions), we coded whether Ellie's shrugs were: self-oriented, otheroriented, or unclear (when we could not decide).

The results are presented in Figure 4.

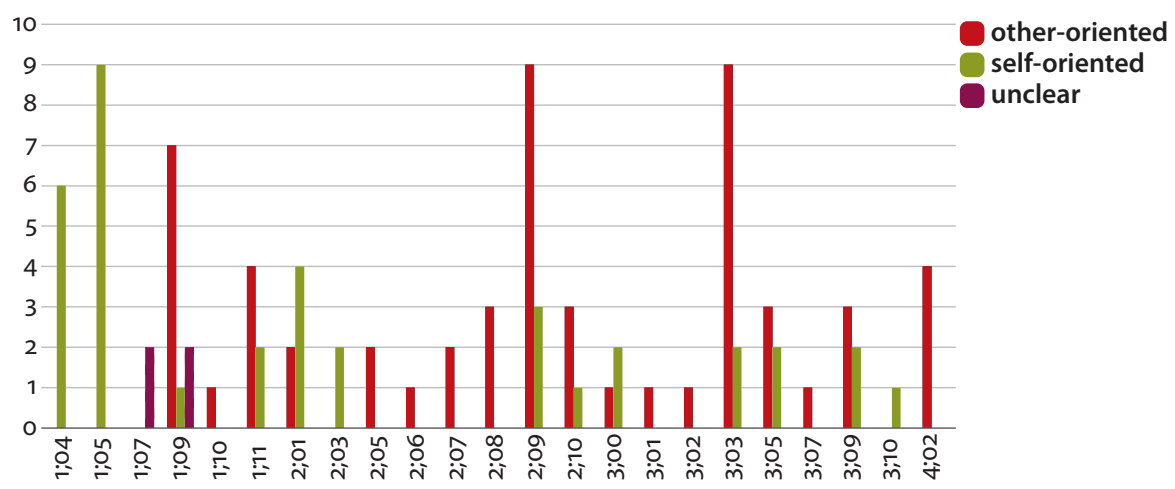

Figure 4. The communicativeness of Ellie's shrugs 
Ellie's first shrugs at 1;04 and 1;05 are just for herself, but they quickly become addressed to her interlocutors, from 1;09 onwards. The unclear cases are located at 1;07 and 1;09: they might indicate a period of transition from self-oriented to addressed shrugs. From 1;09 to 4;00, Ellie's shrugs are mostly communicative, although self-oriented shrugs remain part of her repertoire.

Figure 5 presents the four main functions of shrugs in terms of their (self- or other-) orientation. Two phases stand out: from 1;04 to 1;09, self-oriented shrugs dominate while other-oriented shrugs are scarce and limited to the expression of absence. In contrast, from 1;10 on, other-oriented shrugs are more frequently used than self-oriented ones, and express a larger variety of functions (absence, epistemic and affective meanings). Despite low figures, other-oriented epistemic shrugs are far more frequent (23) than self-oriented ones (4) over the second period. From 1;10, the expression of subjective stances (epistemicity, but also affect) seems to develop as part of a broader development of intersubjectivity.

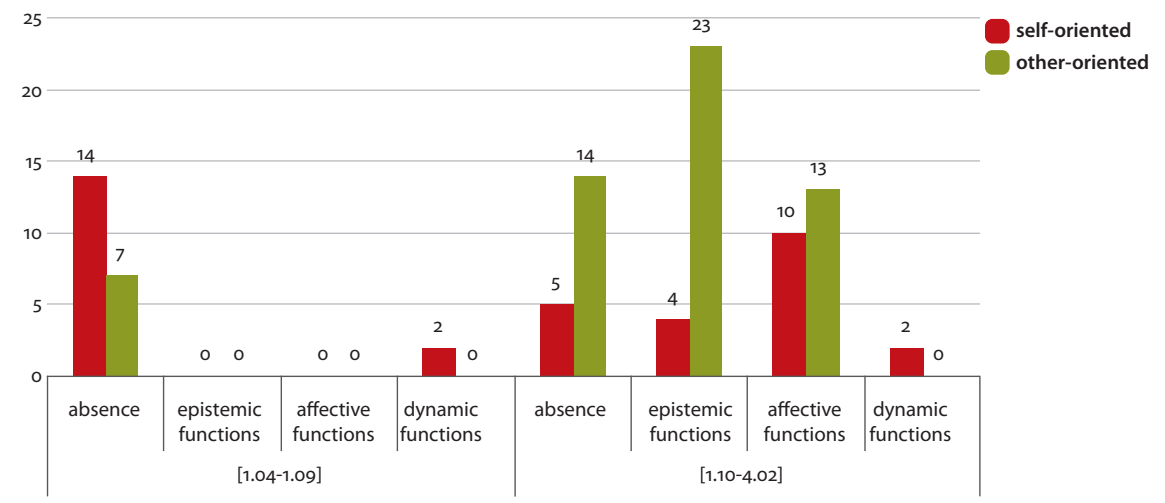

Figure 5. The orientation of shrugs according to their function

\subsection{Form-function patterns? Exploratory statistics}

After coding shrug forms and functions separately, we investigated the possible correlations between specific forms and functions in the data. Exploratory statistics are one reliable way of finding such correlations. Running a multiple correspondence analysis (MCA) in R with the FactoMineR library (Lê, Josse, \& Husson, 2008) provided us with a spatial representation of statistical patterns and correlations in the data, as shown in Figure $6 .{ }^{4}$

The two dimensions presented by the software indicate a fairly high representation of the data (over 30\% in total). These dimensions correspond to the portion

4. To obtain this map, we used two libraries in R: FactoMiner (Lê et al.,2008) and dynGraph. 


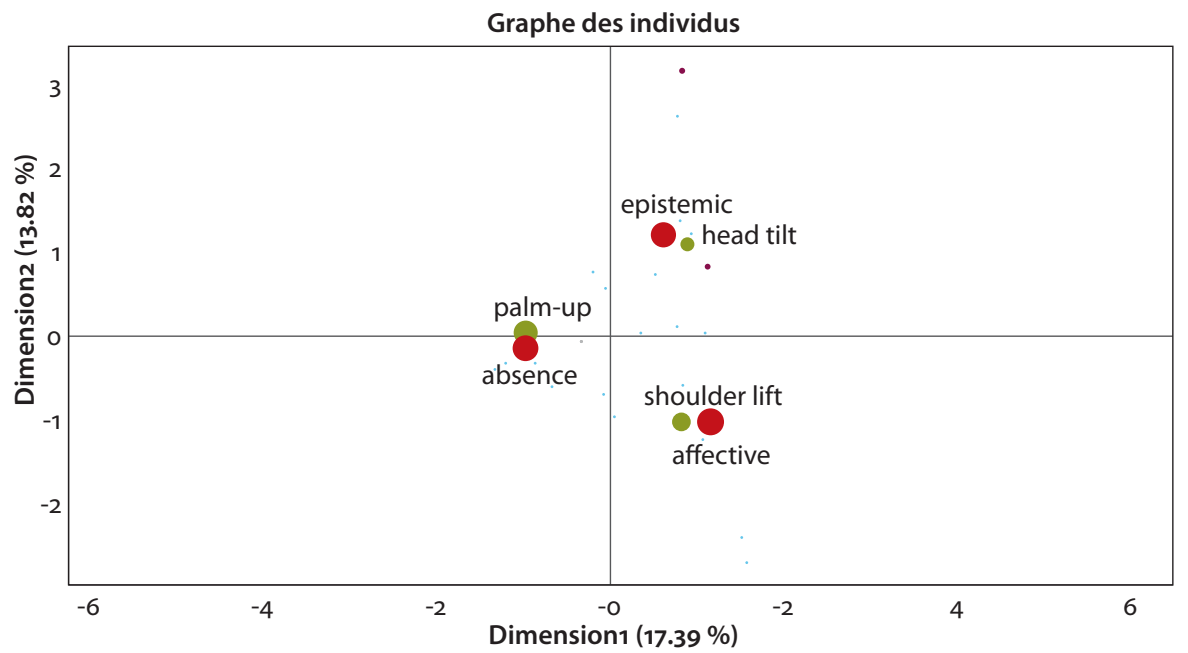

Figure 6. MCA (forms and functions of Ellie's shrug components)

of the data that is visible on the map. The map is a two-dimensional representation of the three-dimensional system of interaction between the variables; it is therefore not possible to get an overview of the whole data on one map (Perdoncin \& Mercklé, 2014). In this representation of the data, correlations between the variables are visible when the different individuals or tokens of each variable get close together. Figure 6 presents the individuals or occurrences of two variables: one deals with the form of the gesture (palm-up, shoulder lift and lateral head tilts) in green and the other deals with the function of the gesture in red. Zooming in, we observe that the tokens of palm-ups, shoulder lifts and lateral head tilts are located in three distinct areas on the map. This shows that the forms are distinct from one other. We observe the same distribution for absence, affective stance and epistemic stance on the second variable. Some striking correlations between forms and functions appear:

- palm-ups are highly correlated with the expression of absence,

- shoulder lifts are highly correlated with affective stance,

- lateral head tilts are highly correlated with epistemic stance.

The dynamic function is not clearly linked with any form, possibly due to the low number of occurrences for incapacity.

The form-function pairings identified thanks to the MCA confirm the various phases previously identified in terms of forms (Figures 1 and 2) and functions (Figure 3) in Ellie's gradual acquisition of shrug components. They are also consistent with the frequency of forms and functions in the data. Indeed, a closer look at our coding shows that Ellie produces 48 palm-up gestures and among them 36 are 
used to convey absence. Therefore three palm-ups out of four in Ellie's production are used to express absence.

The concertina effect identified by Sekali (2012) in the development of complex structures could account for the data at various scales of development. Indeed, as described for another child in Sekali's study, Ellie's communication skills seem to develop in stages, with one mode being more prevalently used during a certain stage, before she reaches the next stage where she is able to combine different modes in a richer, more complex way. Previous work on the development of negation in Ellie's data has shown that she does not replace one modality with the other; rather, the two systems first develop independently and are later combined by the child (BeaupoilHourdel, 2015; Beaupoil-Hourdel et al., 2015; Morgenstern \& Beaupoil, 2015).

Furthermore, form-function pairings in the data suggest that stages in the use of shrugs can also be identified within a single mode: between 1;04 and 4;00, Ellie's shrugs seem to first mobilise one component at a time, with each component being used to fulfil one specific function. This pattern is in line with our initial hypothesis: Ellie's acquisition of shrug components one by one seems to follow the morphological developmental process described for signed languages (Reilly \& Anderson, 2002). It may be hypothesised that once she has mastered the use of each component after 4;00, further steps of development will appear, with increasingly more complex combinations of components to express a richer diversity of functions.

\section{Qualitative analysis: multimodal wholes}

Besides revealing various stages in the development of forms and functions, systematic coding allowed us to identify more specific multimodal patterns in Ellie's use of shrugs. Between 1;04 and 4;00, Ellie's shrugs are recurrently produced as part of multimodal wholes or chunks (Andrén, 2010; Kendon, 2002): they are repeatedly associated with specific words or phrases for a certain period of time in her life. The succession of these multimodal wholes seems to exemplify the three phases in Ellie's use of shrugs. In this section, we analyse one example of each multimodal whole in detail.

\subsection{Palm-up + "done" or "gone"}

The first recurrent multimodal pattern in the data is the synchronisation of the palm-up with the one-word utterance [də] or [dæ] (for "done"), "done" or "gone" $(n=22)$. Ellie uses this multimodal whole to express absence or to mark the end of a process or activity. 
Ellie's first shrug component is found at 1;04: she combines the palm-up with [də] after she has finished taking off her trousers. She initiates the use of the palmup gesture, alternating it with repetitions of the utterance [ə də], and then both adults who are present take up Ellie's multimodal utterance and try to reformulate her meaning. The mother, who is off-screen filming the scene, reformulates Ellie's utterance as a question: "Are you all done?" Ellie then produces a multimodal utterance by perfectly synchronising the one-word utterance [də] with a palm-up gesture, immediately taken up as a multimodal whole by the grandmother who meta-linguistically comments about it to the mother and the camera "I love this [də]", synchronising "[də]" with a palm-up gesture in her turn. The grandmother's smile confirms her positive assessment of the child's multimodal utterance ("I love"): such a display of positive affect can be received by Ellie as a signal of encouragement for her to keep combining gestures with speech to express herself.

Ellie's multimodal utterance also highlights her awareness of the finite aspect of a process and its result (she comments on the fact that she has finished taking off her trousers). The palm-up emphasises the result of this completed activity: Ellie's empty supine open hands seem to express the absence of an activity that has been going on and is now over. Ellie's first shrugs are thus used to express something concrete in the here and now, in this case an activity that she is involved in. At that early age though, Ellie is not yet using the shrug component as a medium for communication: indeed, her shrug is self-oriented since her gaze is not directed on either interlocutor.

It is interesting that palm-ups should cluster with the expression of absence in Ellie's data. If we consider that the meaning of gestures is rooted in manual actions (e.g. asking for something, receiving), then the meaning of absence associated with palm-ups could indicate that actions grammaticise and become co-verbal gestures, in analogy with the way gestures can grammaticise and become signs in sign languages (Wilcox, 2004).

\subsection{Palm-up + "where...?"}

From 2;01 onwards, Ellie recurrently combines the palm-up with where questions $(n=7)$. An example of this multimodal whole is found at 2;08. Ellie and her mother are preparing to paint a cardboard box, and the mother says: "How big's the box? It's a big box". Ellie takes up her mother's assertion to ask the question: "Where's the big box?" and synchronises this utterance with a palm-up flip. The mother reformulates Ellie's question with the exact same words, inviting Ellie to look for it and locate it. Ellie looks around and, seeing the box, points to it with her index finger, simultaneously saying "There". 
This example (at 2;08) is found during phase 2 (from 2;01 to 3;02), when Ellie has already started to diversify her use of shrug components: she has started using lateral head tilts and shoulder lifts as well. But phase 2 is also a stage of Ellie's communicative development when the overall use of gesture decreases while the use of the speech mode becomes prevalent. The palm-up is the oldest, and hence probably the most stable form in her repertoire of shrug components. This could explain why in a phase when gesture is put on a standby for the benefit of speech development, Ellie combines the oldest and more stable shrug component acquired in phase 1 (the palm-up) with more complex syntax in phase 2 . As in phase 1 , her multimodal utterance is used to comment on the absence of an object in her immediate, concrete environment. But contrary to phase 1, the communicative dimension of her multimodal utterance has developed. Her utterance is clearly other-oriented on many levels, displaying her mastery of interpersonal communication: she uses interrogative syntax with a rising intonation while her gaze is on her addressee, and her utterance is smoothly inserted in the sequentiality of conversational actions as her questions directly take up her interlocutor's previous utterance.

\subsection{Lateral head tilt + "I don't know" or "I can't remember"}

The third recurrent form of multimodal whole that stands out in Ellie's use of shrugs is the combination of a shrug component, usually the head tilt, with a statement of epistemic negation, usually "I don't know" or "I can't remember". Ellie uses this multimodal combination for instance at 3;09. She and her grandmother are taking out old clothes from a box for Ellie to dress up, and the mother is filming them. Ellie takes out an item from the box and inspects it. The mother asks her: "what's that Ell's?". Ellie replies: "don't kno:::w", and perfectly synchronises this utterance with a head tilt to the left. She then drops the item to look for a new one. At that point of development of her communication resources (phase 3), Ellie has acquired three shrug components and is able to combine them with complex verbal utterances. She is now capable of using multimodal constructions to express a more abstract relation to her immediate environment. In this extract, she is not commenting on a concrete feature of the here and now anymore, but expressing a more abstract, subjective, cognitive state that she is in.

5. Vowel lengthening is indicated by a series of colons, following Goodwin and Goodwin (1987). 


\subsection{After 3;03: more complex multimodal utterances}

After Ellie has developed gesture (predominantly in phase 1) and speech (predominantly in phase 2 ), from $3 ; 03$ on she is able to combine resources from both modalities in more complex ways to produce richer multimodal utterances (phase 3), as in the following example. In a recording at 3;05, Ellie is playing with her mother and the grandmother is filming them. As Ellie is holding a toy car, her grandmother asks her: "have you been in that car?". Ellie replies: "Been in Mummy's car though". Ellie synchronises this utterance with a compound shrug including a head tilt combined with lifted shoulders. In terms of gesture phases (Kendon, 2004), the preparation phase for this gesture starts from the beginning of the utterance as the head starts tilting when she starts speaking. The gesture stroke is synchronised with the word "car", on which the shoulders are lifted and the head tilted right to their maximum, and then the articulators are quickly retracted into a more neutral position on "though". Interestingly, the gesture stroke on "car" is not synchronised with the vocal prosodic nucleus, which falls on the first syllable of "Mummy".

This example illustrates how after 3;03 Ellie is able to produce complex multimodal utterances in which speech and gesture supplement each other. The use of "though" indicates that two propositions are opposed. When speech is the only mode used, an adult-like concessive utterance (with $p$ and $q$ being two propositions) constructed with though will usually take the form " $p, q$ though". Looking at speech only might lead one to think that Ellie has not expressed $p$, and does not master this construction yet. However, a multimodal outlook on this data reveals that Ellie does express $p$, although she does so not in speech but in gesture. Her shrug expresses an underdetermined, schematic yet conventionalised meaning of absence and negation (Beaupoil-Hourdel et al., 2015), synchronised with the word "car", which is highlighted by the gesture stroke. As per Kendon (2002), attempting to gloss the whole multimodal utterance (i.e. taking the meanings produced by the interaction between speech and gesture into account) reveals additional meanings that cannot be found in the verbal component only. Ellie's multimodal utterance could be glossed as follows: "I haven't been in that car, I have been in Mummy's car though", or "no, but I have been in Mummy's car". The " $p, q$ though" construction usually classifies $p$ as preconstructed information and $q$ as new, focused information, with the construction being overall $q$-oriented (Morel, 1996; Rossari, 2014). Ellie's utterance suggests that she also masters the notion of polarity embedded in the construction (Ducrot, 1984, 1989, 2001; Marconi \& Bertinetto, 1984). Indeed, she clearly denies her grandmother's previous utterance in $p$ and elaborates on the topic in $q$. Her utterance is $q$-oriented and the verbal-vocal formulation makes $q$ more specific and more salient, while $p$ is backgrounded as less specific and more 
schematic due to its non-verbal realisation. Ellie's meaning seems to be unambiguous for her interlocutors, since they do not attempt to repair her utterance and carry on with the interaction.

Looking at speech only would have led one to think that she has not expressed $p$, while in fact a multimodal approach of the data reveals that not only is she able to use the " $p, q$ though" construction but she can also construct $p$ non-verbally and express it at the same time as a verbal $q$, which would not have been possible using words only. Using gestures and speech simultaneously allows her both to construct meaning vertically and to answer her grandmother's question while expanding on this answer. In this sequence, gesture is not redundant with speech: its meaning and stance function are different from the ones expressed by the spoken component of the utterance.

\section{The role of the input}

\subsection{The input as model}

To what extent does Ellie pick up shrugging from the adults around her? Ellie's mother is the adult that she interacts with most often, hence we document the use of all of her shrugs in the data, whether she is addressing Ellie or not. As part of our constructivist approach (Tomasello, 2003), we document the mother's productions since the input plays a crucial role in the way children express themselves (Clark, 2003; Nelson, 1998). Studying the mother's use of shrugs could give some insight on what gestures Ellie might pick up as a participant or as an overhearer (Goffman, 1981) of adult conversations.

Since the mother is an adult, we assume that the forms and functions of her shrugs are part of a stabilised repertoire of communicational resources. The mother shrugs 26 times in the recordings. All her shrugs except one are lateral head tilts, and the remaining one is a palm-up gesture. Such low numbers prevent the identification of any trend in the mother's gesturing strategies as Ellie grows up from $1 ; 04$ to $4 ; 00$.

Yet the mother's only recorded palm-up casts light on Ellie's multimodal wholes in an interesting way. This gesture is found when Ellie is 2;08. Ellie and her mother are decorating a cardboard box with paint, and looking for a paintbrush. The mother asks: "Where is it gone, Ellie?" and makes a lateral movement with both forearms supine to the sides. In this extract, the mother combines the palm-up with the words "where" and "gone" in a question addressed to Ellie. The mother's high-pitched intonation as well as her large, salient gesture suggests that her utterance is a form of multimodal motherese, i.e. designed in specific ways to 
facilitate the child's understanding (Lakshmi, Gogate, Bahrick, \& Watson, 2000). Furthermore, this unique token of a palm-up performed by the mother is combined with both "where...?" and "gone", two words that Ellie typically associates recurrently with palm-ups to construct multimodal wholes before 3;00. She may have picked them up from surrounding adults who gesture around or for her.

Ellie's shrugs rely on palm-ups before the age of 2;00, after which she gradually starts using other forms such as shoulder lifts and lateral head tilts, while her mother uses mostly lateral head tilts. If Ellie's gestures develop through adult imitation they could also emerge from her own actions.

\subsection{Adult speech about the child's gestures}

Ellie might be picking up some of her gestures from the adults that surround her the way she picks up words and intonations. Yet one fundamental difference should be noted in the way the surrounding adults react to the development of her gestures compared with that of her speech. They do not repair her gestures the way they repair her speech: in the data, they never correct features (shape, location, orientation) of a kinetic form produced by the child, the way deaf signing parents would provide visual feedback for their deaf signing child (Holzrichter \& Meier, 2000; Morgan, Barrett-Jones, \& Stoneham, 2007).

The influence of the surrounding adults' speech on the child's gestures seems to be of a different nature: although they do not repair Ellie's gestures, they recurrently produce specific speech about them, according to the following pattern: Ellie spontaneously produces a gesture form, or performs a body movement, which is interpreted by the adult in speech or in speech and gesture as bearing some communicative meaning. Several instances of this pattern are found early in the data, before Ellie is 2;00. This is a time when Ellie is not yet capable of systematically producing verbal utterances and adults focus on the child's physical attitude to try and understand the expression of complex, modal meanings.

The first tokens of a shrug component in Ellie's data (at $1 ; 04$ ) is actually a palm-up that is immediately taken up and multimodally reformulated by the adult next to her, in that case the grandmother. ${ }^{6}$ One month later, a similar pattern is observed again. Ellie $(1 ; 05)$ is playing with a small pushchair for dolls and her grandmother is filming her. From behind the camera, the grandmother asks Ellie: "Are you going shopping? Where's your basket?" Ellie does not reply with speech, but produces a visual response with gesture and movement: she starts looking around with both her hands supine, and walks away from the camera, keeping her palms up as she looks for her basket. Following her with the camera, her grandmother

6. This example is analysed in Section 4.1 . 
reformulates Ellie's physical attitude twice in speech: "We don't know where it is, do we Ellie?" and then, as an aside to the camera: "Oh, she says, I don't know". In the first reformulation, the grandmother uses the pronoun "we", positioning herself as speaking in unison with Ellie. The grandmother is both speaking as a mouthpiece for Ellie by voicing what she projects as the little girl's communicative intentions, and addressing Ellie, as suggested by the second "we" in the question tag "do we, Ellie?". And yet, this tag question is not so much requesting Ellie's confirmation as imposing a meaning on Ellie, as indicated by the falling tone used by the grandmother on the tag (Gaudy-Campbell, 2000; Tottie \& Hoffman, 2006): for the grandmother, this reformulation is doubtlessly the right and only possible meaning of Ellie's physical attitude. The second verbal reformulation of Ellie's posture is a first person gloss in the form of direct speech: "Oh, she says, I don't know". Ellie's physical behaviour is equated with speech by the discourse verb "she says", suggesting that her posture has exactly the same pragmatic functions as a verbal utterance (Morgenstern \& Beaupoil, 2015). At such an early stage of Ellie's communicative development, it is difficult to say whether her movements are actually produced with a communicative intent. What is striking though is that adult speech about her posture imbues her gestures with very specific, conventionalised meanings, inscribing Ellie's physical behaviour in the realm of communication from a very young age.

In another example, also at 1;05, Ellie is attempting to grab a lid from the top drawer of the dishwasher. As she fails to do so, she turns away with a palm-up gesture, showing an empty hand, looking at nobody in particular. The grandmother, who is filming, immediately interprets this behaviour as bearing communicative intent, reformulating Ellie's attitude as an expression of incapacity: "Can't do it, she says". Equating gesture with speech once more, the adult interprets the child's movement as a visuo-gestural utterance, here as an expression of dynamic modality. The adult's interpretation is no accidental guess: it is rooted in the adult repertoire of emblems, in which the palm-up is culturally conventionalised as an expression of helplessness/ incapacity (Boutet, 2008).

These examples cast light on the processes that might foster the emergence of conventionalised gestures such as emblems. From a very young age, the child is addressed very specific verbal reformulations of some of her own movements that resemble adult-like emblems. Such adult speech about the child's actions could lay the basis for the ontogenetic conventionalisation (Tomasello \& Call, 1997; Tomasello, Carpenter, Call, Behne, \& Mol, 2005) of initially accidental movements rooted in the child's actions that are gradually recycled as visual communicational resources. This could be one way gestural emblems develop: a child appropriates culturally established gesture forms quite early on and assimilates them with increasingly more stable and specific, shared meanings. 


\section{Discussion}

Between the emergence of shrug components at 1;04 and the age of 4;00, three phases can be identified in Ellie's use of shrugs:

Phase 1 (from 1;04 to 2;00): development and prevalent use of gesture over speech; Phase 2 (from 2;01 to 3;02): stabilisation of gesture use (its development is put "on hold") while the development of speech takes over; acquired gesture forms are used in richer speech contexts;

Phase 3 (from 3;03 to 4;00): gesture use increases again, speech and gesture develop together and speech-and-gesture combinations become more complex.

Each phase is epitomised by the recurrent use of a multimodal whole, in which the shrug component is combined with a specific word or phrase:

Phase 1:palm-up + "done" or "gone". The child comments on a concrete aspect of her immediate environment, usually just for herself.

Phase 2:palm-up + "where...?". The child comments on a concrete aspect of her immediate environment, but her utterance is more complex and explicitly designed for an interlocutor.

Phase 3:lateral head tilt + "I don't know" or "I can't remember". The child makes an abstract statement about her cognitive rapport to her immediate environment and interlocutors. She also starts developing richer, more complex speech-and-gesture utterances (such as the multimodal concession construction “ $p, q$ though”).

Whereas McNeill (2014) recently posited a clear-cut separation between an initial acquisition of gesture only and subsequent acquisition of speech-gesture combinations, with the gesture-only productions going extinct when the speech-gesture combinations take over, Ellie's use of gesture and speech rather suggests a continuous and dynamic development of the two modes, with speech and gesture developing one at a time and side by side, and gradually combining in increasingly complex utterances. Ellie's gestures are not just paving the way for the development of speech: rather, the two modes develop in an integrative way, with stages where one mode develops more than the other. This process is reminiscent of the "concertina effect" proposed by Sekali (2012) to account for the dynamic patterns of syntactic expansion, integration and diversification of constructions in speech. In line with Sekali's analysis, we suggest that such dynamic patterns characterise not only syntactic expansion but also mode expansion (i.e. for communication modes like actions, gestures and speech).

Shrug components are acquired one at a time, from distal to proximal articulators: palm-ups emerge first at 1;04, shoulder lifts follow at $1 ; 11$, and lateral head 
tilts appear from 2;03. Exploratory statistics performed on our data in $\mathrm{R}$ reveal that this step-by-step acquisition is not just formal but also morphological. Each component realised in isolation is clearly related to a specific function in the development of Ellie's gesture repertoire:

- Palm-ups are highly correlated with the expression of absence;

- Shoulder lifts are highly correlated with the expression of affect;

- Lateral head tilts are highly correlated with the expression of epistemic stance.

These findings suggest that the development of a compound gestural enactment such as the shrug is highly similar to the morphological development of multicomponent signs among deaf children (Reilly \& Anderson, 2002).

\section{Conclusion}

The different shrug components seem to have various origins. The first component to appear, palm-ups, could to some extent derive from the child's actions of discovering and manipulating objects with her hands. The palm-up gesture, predominantly used to express absence, seems to work as a metonymic extension of an empty hand that has held, or that begs to receive, an object (as per Müller, 2004 and Streeck, 1994). As such, it could be rooted in an originally non-linguistic form (an action of giving or taking) recycled to play a linguistic function, according to a process described for the acquisition of non-manual morphology in sign languages (Reilly \& Anderson, 2002). The palm-up is also very close in both form and function to the ASL and LSF signs for "I want", in which open supine hands make a movement downwards, emphasising the emptiness of the palms. Even though the mother almost never uses the palm-up in the recordings, the adults surrounding Ellie use palm-ups as part of their conventional gesture repertoire (Beaupoil-Hourdel, 2015). Ellie could also take up this gesture form from this input. Isolated shoulder lifts and lateral head tilts are not directly used to manipulate objects: their communicative functions are less likely derived from the child's actions, and rather seem to originate in the imitation of adults' gestures. This is consistent with the development of these gestures' communicativeness. The first components, palm-ups, are self-oriented in contexts when the child is still mostly making contact with the world around her, while shoulder lifts and lateral head tilts appear only once Ellie has started using other-oriented shrug components. As time goes by, Ellie's shrug components resemble more and more the ones that are most regularly used by her mother, namely lateral head tilts. The data seems to suggest that the more the child's gestures are directed towards an interlocutor, the more they are inspired by the interlocutor's own gestures. 
The order of appearance of Ellie's shrug components could also have a functional motivation. Since each shrug component is connected with a specific function, Ellie starts with the concrete function (absence) expressed by palm-ups because, from a developmental perspective, she is too young to take a stance before $1 ; 10$; therefore she simply reacts to the environment by showing that a given object is in the immediate situational context or not. After that age, she gradually turns to shoulder lifts and head tilts (components linked with stance-taking functions) as her need to position herself (inter)subjectively starts to emerge.

The acquisition of gesture emblems seems to rely on two processes: not only the child's imitation of adults' gestures but also the adults' speech on the child's gestures. When the child happens to perform a movement that resembles a culturally established gesture emblem, the adult takes it up as a gesture and immediately imbues it with meaning by equating it with speech (e.g. "Oh, she says, I don't know"). From the very first occurrence of a shrug component (a palm-up at 1;04), the adult takes up her multimodal utterance by reproducing it with increased positive affect (smile + "I love this" when imitating the child). Such positive feedback encourages the child to keep using this gesture form for similar meanings in similar contexts. From one interaction to the next, adults take up some of the child's actions as communicatively meaningful by attributing culturally conventionalised meanings to these forms. In all, the use of shrug components seems inscribed in an interaction-acquisition cycle. Gestures first help children enter communication through actions and movement, and then interactional contexts with adults help children refine their communicative use of gesture.

Studying the emergence of a young child's shrugs casts a new light on the use of shrugging among adults. In a previous study of British adult speakers (Debras, 2013), we had reached the conclusion that distance and disengagement constituted the basic semantic-pragmatic theme of shrugging among adults. In line with Streeck (2009), we thought that the shrug's culturally conventional meaning originated in a holistic, schematic representation of a movement of physical disengagement from potential action on the part of the speaker. The child data suggest something slightly different, and more complex. The first component to appear is the palm-up gesture. Its basic meaning, the expression of absence, could be rooted in the actional experience of the absence of an object in one's hand. Absence could function as a basic experiential schema (Cienki, 2005) that is gradually extended to more intersubjective and abstract meanings as the individual's communicative and cognitive skills develop: the shrug gradually comes to express incapacity (absence of capacity), ignorance (absence of personal knowledge) and later common ground (absence of new shared information). This expansion from concrete to abstract, subjective meanings could be interpreted as a form of grammaticalisation of this posture over time. These various meanings can migrate from one shrug 
component to another, because these forms (palm-up flip, shoulder lift, lateral head tilt) share common physiological features (Boutet, 2008) that make them part of the same gesture family.

\section{Acknowledgements}

The authors would like to thank the two guest editors of this special issue, Michèle Guidetti and Aliyah Morgenstern, as well as two anonymous reviewers for their invaluable advice, Eve Sweetser and all the participants of the Workshop "Linguistique cognitive et multimodalité" organized by Eric Mélac at Sorbonne Nouvelle in Paris on December 19th, 2014 as well as Charles Goodwin, Marjorie Goodwin and Erica Cartmill for their helpful suggestions and rich discussion.

\section{References}

Andrén, M. (2010). Children's gestures from 18 to 30 months. Travaux de l'Institut de Linguistique de Lund 50. Lund: Lund University Press.

Beaupoil-Hourdel, P. (2015). Multimodal acquisition and expression of negation. Unpublished thesis manuscript. Sorbonne Nouvelle: Paris.

Beaupoil-Hourdel, P., Morgenstern, A., \& Boutet, D. (2015). A child's multimodal negations from 1 to 4: The interplay between modalities. In P. Larrivée \& C. Lee (Eds.), Negation and polarity: Cognitive and experimental perspectives (pp. 95-123). Switzerland: Springer International Publishing.

Bello, A., Caselli, M. -C., Pettenati, P., \& Stefanini, S. (2010). Pin G parole in Gioco : Una prova di comprensione e produzione lessicale per la prima infanzia. Firenze: Giunti OS.

Blondel, M., Boutet, D., Beaupoil-Hourdel, P., \& Morgenstern, A. (2017). La négation chez les enfants signeurs et non signeurs : Des patrons gestuels communs. In M. Guidetti \& A. Morgenstern (Eds.), Language Interaction and Acquisition 8(1), 143-182. doi: 10.1075/lia.8.1.07blo

Boutet, D. (2008). Une morphologie de la gestualité : Structuration articulaire. Cahiers de Linguistique Analogique 5, 81-115.

Boutet, D. (2010). Structuration physiologique de la gestuelle : Modèle et tests. LIDIL 42, 77-96.

Capirci, O., Iverson, J., Pizzuto, E., \& Volterra, V. (1996). Gestures and words during the transition to two-word speech. Journal of Child Language 23(3), 645-673. doi: $10.1017 /$ S0305000900008989

Channon, R., \& van der Hulst, H. (Eds.). (2011). Formational units in Sign Languages. Göttingen: de Gruyter. doi: 10.1515/9781614510680

Cienki, A. (2005). Image schemas and gesture. In B. Hampe (Ed.), From perception to meaning: Image schemas in Cognitive Linguistics (pp. 421-442). Berlin: Mouton de Gruyter. doi: 10.1515/9783110197532.5.421

Clark, E. V. (1978). From gesture to word: On the natural history of deixis in language acquisition. In J. Seymour Bruner \& A. Garton (Eds.), Human growth and development (pp. 85120). Wolfson College Lectures 1976. Oxford: Oxford University Press. 
Clark, E. V. (2003). First language acquisition. New York: Cambridge University Press.

Darwin, C. (1872). The Expression of Emotions in Man and Animals. (Accessed August 2015) http://www.gutenberg.org/files/1227/1227-h/1227-h.htm doi: 10.1037/10001-00o

Debras, C. (2013). Multimodal Stance-taking. Unpublished PhD dissertation, Sorbonne Nouvelle University, Paris.

Debras, C. (to appear). The shrug: forms and meanings of a compound enactment. Gesture 17.

Ducrot, O. (1984). Le Dire et le dit. Paris: Editions de Minuit.

Ducrot, O. (1989). Logique, structure, énonciation: lectures sur le langage. Paris: Editions de Minuit.

Ducrot, O. (2001). Quelques raisons de distinguer locuteurs et énonciateurs. Polyphonie - linguistique et littéraire 3, 19-41.

Efron, D. (1941). Gesture and environment. New York: King's Crown's Press.

Ekman, P., \& Friesen, W. V. (1969). The Repertoire of nonverbal behavior: Categories, origins, usage, and coding. Semiotica 1(1), 49-98. doi: 10.1515/semi.1969.1.1.49

Englebretson, R. (2007). Stancetaking in discourse: An introduction. In R. Englebretson (Ed.), Stancetaking in discourse: Subjectivity, evaluation, interaction (pp. 2-25). Amsterdam: Benjamins. doi: 10.1075/pbns.164.02eng

Filhol, M., Hadjadj, M. N., \& Choisier, A. (2014). Non-manual features: The right to indifference. Proceedings of Language resource and evaluation conference (LREC), 6th workshop on the representation and processing of Sign Language: Beyond the manual channel (pp. 49-54). Reykjavik.

Gaudy-Campbell, I. (2000). Le question-tag descendant : Marque de questionnement ou d'égocentrage? Anglophonia 8, 168-180.

Givens, D. (1977). Shoulder shrugging: A densely communicative behavior. Semiotica 19(1/2), 13-28.

Goffman, E. (1981). Forms of talk. Philadelphia: University of Pennsylvania Press.

Goldin-Meadow, S. (2005). The resilience of language: What gesture creation in deaf children can tell us about how all children learn language. New York: Psychology Press.

Goldin-Meadow, S., Goodrich, W., Sauer, E., \& Iverson, J. (2007). Young children use their hands to tell their mothers what to say. Developmental Science 10(6), 778-785. doi: 10.1111/j.1467-7687.2007.00636.x

Goodwin, C., \& Goodwin, M. H. (1987). Concurrent operations on talk: Notes on the interactive organization of assessments. IPRA Papers in Pragmatics 1(1), 1-54. doi: 10.1075/iprapip.1.1.01goo

Holzrichter, A. S., \& Meier, R. P. (2000). Child-directed signing in American Sign Language. In C. Chamberlain, J. P. Morford, \& R. I. Mayberry (Eds.), Language acquisition by eye: Early language acquisition (pp. 25-40). Mahwah: Erlbaum.

Iverson, J. M. (2010). Developing language in a developing body: The relationship between motor development and language development. Journal of Child Language 37, 229-261. doi: 10.1017/So305000909990432

Iverson, J. M., \& Goldin-Meadow, S. (2005). Gesture paves the way for language development. Psychological Science 16, 367-371. doi: 10.1111/j.0956-7976.2005.01542.x

Iverson, J., Capirci, O., Volterra, V., \& Goldin-Meadow, S. (2008). Learning to talk in a gesturerich world: Early communication of Italian vs. American children. First Language 28, 164181. doi: $10.1177 / 0142723707087736$

Kendon, A. (2002). Some uses of the head shake. Gesture 2(2), 147-182. doi: 10.1075/gest.2.2.03ken 
Kendon, A. (2004). Gesture: Visible action as utterance. Cambridge: Cambridge University Press. doi: 10.1017/CBO9780511807572

Lakshmi, J. Gogate, L. E. Bahrick, \& Watson, J. D. (2000). A Study of multimodal motherese: The role of temporal synchrony between verbal labels and gestures. Child Development 71(4), 878-894. doi: 10.1111/1467-8624.00197

Lê, S., Josse, J., \& Husson, F. (2008). FactoMineR: An R package for multivariate analysis. Journal of Statistical Software 25(1), 1-18. doi: 10.18637/jss.v025.io1

LeBaron, C. \& Streeck, J. (2000). Gesture, knowledge and the world. In D. McNeill (ed.), Language and Gesture (pp. 118-138). Cambridge: Cambridge University Press. doi: 10.1017/CBO9780511620850.008

Marconi, D. \& Bertinetto, P. M. (1984). Analisi di ma. (Parte prima : Semantica e pragmatica). Lingua e stile 19(2), 223-258.

Maury-Rouan, C. (2011). 'Voices' and bodies: Investigating nonverbal parameters of the participation framework. In G. Stam \& M. Ishino (Eds.), Integrating gestures: The interdisciplinary nature of gesture (pp. 309-320). Amsterdam: Benjamins.

McNeill, D. (2014). Gesture-speech unity: Phylogenesis, ontogenesis, and microgenesis. Language, Interaction, Acquisition 5(2), 137-184. doi: 10.1075/lia.5.2.01mcn

McWhinney, B. (2000). The CHILDES project: Tools for analysing talk (3rd ed., Vol. 2). Mahwah: Erlbaum.

Meier, R. P., Mauk, C. E., Cheek, A., \& Moreland, C. J. (2008). The form of children's early signs: Iconic or motoric determinants? Language Learning and Development 4(1), 63-98. doi: $10.1080 / 15475440701377618$

Morel M. -A. (1996). La concession en français. Paris: Ophrys.

Morgan, G., Barrett-Jones, S., \& Stoneham, H. (2007). The first signs of language: Phonological development in British Sign Language. Applied Psycholinguistics 28, 3-22. doi: 10.1017/S0142716407070014

Morgenstern, A. (2014). Children's multimodal language development. In C. Fäcke (Ed.) Manual of language acquisition (pp. 123-142). Berlin/Boston: De Gruyter.

Morgenstern, A., \& Beaupoil, P. (2015). Multimodal approaches to language acquisition through the lens of negation. Vestnik of Moscow State University. Linguistics and literary studies 6 (717), 435-451. Special issue on discourse as social practice.

Morgenstern, A., \& Parisse, C. (2012). The Paris Corpus. French Language Studies 22(1), 7-12. doi: 10.1017/So95926951100055X

Morris, D. (1994). Bodytalk: A worldguide to gesture. London: Jonathan Cape.

Müller, C. (2004). Forms and uses of the palm up open hand: A case of a gesture family? In C. Müller \& R. Posner (Eds.), The semantics and pragmatics of everyday gestures, Proceedings of the Berlin conference, April 1998 (pp. 233-256). Berlin: Weidler Buchverlag.

Nelson, K. (1998). Language in cognitive development: The emergence of the mediated mind. Cambridge: Cambridge University Press.

Palmer, F.R. (2001). Mood and Modality. Cambridge: Cambridge University Press.

Perdoncin, A., \& Mercklé, P. (2014). Représenter graphiquement les résultats d'une analyse factorielle avec $R$. http://quanti.hypotheses.org/930/

Pettenati, P., Stefanini, S., \& Volterra, V. (2010). Motoric characteristics of representational gestures produced by young children in a naming task. Journal of Child Language 37, 887-911. doi: $10.1017 /$ S0305000909990092

Piaget, J. (1952). The origins of intelligence in children. New York: Norton. doi: 10.1037/11494-000 
Reilly, J., \& Anderson, D. (2002). The acquisition of non-manual morphology in ASL. In G. Morgan \& B. Woll (Eds.), Directions in sign language acquisition (pp. 159-182). Amsterdam: Benjamins. doi: 10.1075/tilar.2.10rei

Rossari, C. (2014). How does a concessive value emerge? In C. Ghezzi \& P. Molinelli (Eds.), Pragmatic markers from Latin to Romance languages: Studies in Diachronic and Historical Linguistics (pp. 237-259). Oxford: Oxford University Press. doi: 10.1093/acprof:0so/9780199681600.003.0013

Sekali, M. (2012). The emergence of complex sentences in a French child's language from 0;10 to 4;01: Causal adverbial clauses and the concertina effect. Journal of French Language Studies 22(1), 115-141. doi: 10.1017/So959269511000615

Shaw, E. (2013). Gesture in multiparty interaction: A study of embodied discourse in spoken English and American Sign Language. Unpublished thesis manuscript, Georgetown University, Washington DC.

Stefanini, S., Caselli, M. -C., \& Volterra, V. (2007). Spoken and gestural production in a naming task by young children with Down Syndrome. Brain and Language 101(3), 208-221. doi: 10.1016/j.bandl.2007.01.005

Stefanini, S., Bello, A., Caselli, M. -C., Iverson, J. M., \& Volterra, V. (2009). Cospeech gestures in a naming task: Developmental data. Language and Cognitive Processes 24(2), 168-189. doi: $10.1080 / 01690960802187755$

Streeck, J. (1994). 'Speech-handling': The metaphorical representation of speech in gestures. A cross-cultural study. University of Texas, Austin: Unpublished manuscript.

Streeck, J. (2009). Gesturecraft: The manu-facture of meaning. Amsterdam: Benjamins. doi: $10.1075 / \mathrm{gs} .2$

Sutton-Spence, R., \& Woll, B. (1999). The Linguistics of British Sign Language. Cambridge: Cambridge University Press. doi: 10.1017/CBO9781139167048

Tennant, R., \& Gluszak Brown, M. (1998). The American Sign Language handshape dictionary. Washington DC: Gallaudet University Press.

Tomasello, M. (2003). Constructing a language: A usage-based theory of language acquisition. Cambridge, MA: Harvard University Press.

Tomasello, M., \& Call, J. (1997). Primate cognition. Oxford: Oxford University Press.

Tomasello, M., Carpenter, M., Call, J., Behne, T., \& Moll, H. (2005). Understanding and sharing intentions: The origins of cultural cognition. Behavioral and Brain Sciences 28(5), 675-691. doi: $10.1017 /$ So140525X05000129

Tottie, G., \& Hoffmann, S. (2006). Tag questions in British and American English. Journal of English Linguistics 34(4), 283-311. doi: 10.1177/0075424206294369

Valli, C., \& Lucas, C. (2000). Linguistics of American Sign Language: An introduction (3rd Ed.). Washington: Gallaudet University Press.

Wilcox, S. (2004). Gesture and language. Cross-linguistic and historical data from signed languages. Gesture 4(1), 43-73. doi: 10.1075/gest.4.1.04wil

Zlatev, J., \& Andrén, M. (2009). Stages and transitions in children's semiotic development. In J. Zlatev, M. Andrén, C. Lundmark \& M. Johansson Flack (Eds.), Studies in Language and Cognition (pp. 380-401). Newcastle: Cambridge Scholars. 


\section{Résumé}

Dans cet article, nous analysons le développement de la posture composite du shrug (qui peut combiner une supination des paumes ouvertes, un haussement des épaules et un mouvement latéral de la tête), dans un corpus d'interactions spontanées entre une fillette au développement typique, Ellie, et sa maman, filmées à la maison une heure par mois entre les dix mois et les quatre ans d'Ellie. Les 124 occurrences de shrug obtenues après un codage systématique du corpus fournissent des résultats en termes de formes, de fonctions et d'input. Les premiers composants du shrug utilisés par Ellie émergent de ses actions; elle acquiert ces composants un par un, et en commençant par les mouvements des mains : ces trois aspects rappellent les étapes de l'acquisition de signes composites par des enfants sourds du même âge qu'elle (Reilly \& Anderson, 2002 pour l'ASL). Exprimant d'abord l'absence à partir de 1;04, les shrugs d'Ellie développent d'autres fonctions tant épistémiques que non épistémiques (affectives et dynamiques). Le rôle des adultes est prégnant, car en attribuant un équivalent verbal aux mouvements d'Ellie, ils contribuent à l'émergence des fonctions communicatives du shrug comme emblème gestuel (Ekman \& Friesen, 1969).

\section{Authors' addresses}

Pauline Beaupoil-Hourdel

3 rue Jean-Baptiste Clément

94800 Villejuif

France

pauline.beaupoil@sorbonne-nouvelle.fr
Camille Debras

Département d'études anglophones UFR LCE Université Paris Nanterre

200 avenue de la République

92000 Nanterre

France

cdebras@u-paris10.fr 